\title{
Deletion of the Donor Splice Site of Intron 4 in the Glucokinase Gene Causes Maturity-onset Diabetes of the Young
}

\author{
Fang Sun, * Bertrand Knebelmann," Maria E. Pueyo," Habib Zouali, * Suzanne Lesage, * Martine Vaxillaire, " Philippe Passa," \\ Daniel Cohen, * Gilberto Velho, * Corinne Antignac," and Philippe Froguel" \\ *Centre d'Etude du Polymorphisme Humain and Genethon, Paris; ${ }^{\ddagger}$ Institut National de la Santé et de la Recherche Medicale U-367, \\ Paris; ${ }^{\S}$ Service d'Endocrinologie de l'hôpital Saint-Louis, Paris; and "Institut National de la Santé et de la Recherche Medicale U-192, \\ Hôpital Necker, Paris, France
}

\begin{abstract}
Missense and nonsense mutations in the glucokinase gene have recently been shown to result in maturity-onset diabetes of the young (MODY), a subtype of non-insulin-dependent diabetes mellitus with early age of onset. Glucokinase catalyzes the formation of glucose-6-phosphate and is involved in the regulation of insulin secretion and integration of hepatic intermediary metabolism. Nucleotide sequence analysis of exon 4 and its flanking intronic regions of the glucokinase gene, in four hyperglycemic individuals of a MODY family, revealed a deletion of 15 base pairs, which removed the $t$ of the gt in the donor splice site of intron 4 , and the following 14 base pairs. This deletion resulted in two aberrant transcripts, which were analyzed by reverse transcription of RNA from lymphoblastoid cells obtained from a diabetic patient. In one of the abnormal transcripts, exon 5 is missing, while in the other, the activation of a cryptic splice site leads to the removal of the last eight codons of exon 4 . This intronic deletion in a donor splice site seems to cause a more severe form of glucose intolerance, compared with point mutations described in glucokinase. This might be due to a more pronounced effect on insulin secretion. (J. Clin. Invest. 1993. 92:1174-1180.) Key words: aberrant transcripts • cryptic site • exon skipping • illegitimate transcription
\end{abstract}

\section{Introduction}

Non-insulin-dependent diabetes mellitus (NIDDM) ${ }^{1}$ is a heterogeneous disorder of glucose homeostasis characterized by defects in insulin secretion and insulin action (1). The familial aggregation of NIDDM and the high concordance in identical twins indicate the important contribution of heredity to the development of the disease (2). Although most forms of NIDDM do not exhibit simple mendelian inheritance, a sub-

Address correspondence to Dr. Philippe Froguel, CEPH, 27 rue Juliette Dodu, 75010 Paris, France.

Received for publication 12 January 1993 and in revised form 26 April 1993.

1. Abbreviations used in this paper: GCK, glucokinase; IVGTT, intravenous glucose tolerance test; MODY, maturity-onset diabetes of the young; NIDDM, non-insulin-dependent diabetes mellitus; OGTT, oral glucose tolerance test; PM, point mutation; RT, reverse transcription; SSCP, single-strand conformation polymorphism.

J. Clin. Invest.

(c) The American Society for Clinical Investigation, Inc.

0021-9738/93/09/1174/07 \$2.00

Volume 92, September 1993, 1174-1180 type of NIDDM with an early age of onset, maturity-onset diabetes of the young (MODY) is characterized by a clear autosomal dominant transmission (3).

Close linkage between MODY and the glucokinase locus on chromosome $7 p$ has recently been demonstrated in a French cohort and in one English MODY family (4, 5). 16 different nonsense and missense mutations in the glucokinase gene have been identified in affected members of these MODY families (6-9). These mutations were shown to impair the enzymatic activity of the encoded protein (10). The glycolytic enzyme glucokinase (GCK, ATP:D-hexose 6-phosphotransferase, EC 2.7.1.1.) is specifically synthesized in the liver and in pancreatic beta cells. It plays a key role in the regulation of glucose homeostasis: in the hepatocytes, the phosphorylation of glucose by glucokinase facilitates the uptake and metabolism of glucose by maintaining a gradient for glucose transport into these cells, thereby regulating hepatic glucose disposal. In beta cells, glucokinase appears to comprise part of the glucose-sensing mechanism and to be involved in the regulation of insulin secretion (11-13).

Here we report an intronic deletion in the GCK gene in a MODY family, which affects a donor splice site. Since GCK expression is tissue specific, we had to investigate the effects of this intronic deletion on the structure of GCK mRNA by amplification of the GCK illegitimate transcripts present in lymphoblastoid cells.

\section{Methods}

Subjects. Family information and clinical data were obtained from seven members of the family F423 (Table I). This family belongs to a panel of MODY kindreds collected in France through a multimedia campaign (14). MODY was ascertained in the kindred by the presence of NIDDM in three consecutive generations and three patients diagnosed before $25 \mathrm{yr}$ of age. Glucose tolerance status was evaluated by an oral $75 \mathrm{~g}$ glucose tolerance test (OGTT; Table II). Four out of seven individuals were considered to be affected. Individuals N2687, N2234, and $\mathrm{N} 2235$ presented with overt diabetes mellitus (fasting plasma glucose higher than $7.8 \mathrm{mmol} /$ liter or a 2-h plasma glucose higher than $11.1 \mathrm{mmol} /$ liter). Individual N1966 presented with impaired glucose tolerance (fasting plasma lower than $7.8 \mathrm{mmol} /$ liter and 2-h plasma glucose higher than $7.8 \mathrm{mmol} /$ liter and lower than $11.1 \mathrm{mmol} /$ liter) according to the World Health Organization criteria (15). Individual $\mathrm{N} 2687$, previously unknown to be diabetic, was diagnosed during this study.

Mean age of affected individuals was $34 \pm 19 \mathrm{yr}$ (mean $\pm \mathrm{SD}$; Table I). All of them had chronic hyperglycemia diagnosed before the age of 25 except for one individual $(25 \pm 10 \mathrm{yr})$. Time elapsed since diagnosis was $9 \pm 9$ yr. All were of normal body wt (body mass index: $19.9 \pm 3.1$ $\mathrm{kg} / \mathrm{m}^{2}$ ). Apart from chronic hyperglycemia, all were in good general health according to physical examination and routine blood and urine biochemical screening. No patient had proteinuria or a raised serum creatinine. Individuals N2687, N2234, and N2235 were taking an oral 


\begin{tabular}{|c|c|c|c|c|c|c|}
\hline Patients & Sex & Age & BMI & $\begin{array}{c}\text { Glucose } \\
\text { tolerance } \\
\text { status }\end{array}$ & $\begin{array}{c}\text { Age of } \\
\text { diagnosis }\end{array}$ & Treatment \\
\hline & & $y r$ & $\mathrm{~kg} / \mathrm{m}^{2}$ & & $y r$ & \\
\hline N1966 & $\mathbf{M}$ & 16 & 16.7 & IGT & 10 & Diet \\
\hline N2234 & $\mathbf{M}$ & 44 & 21.0 & DM & 22 & Sulfonylurea \\
\hline N2235 & $\mathbf{M}$ & 19 & 18.2 & DM & 12 & Sulfonylurea \\
\hline N2687 & $\mathbf{M}$ & 56 & 23.7 & DM & 55 & Sulfonylurea \\
\hline $\mathrm{F} 423(\mathrm{~m} \pm \mathrm{SD})$ & & $34 \pm 19$ & $19.9 \pm 3.1$ & & $25 \pm 10$ & \\
\hline PM patients $(n=6 ; \mathrm{m} \pm \mathrm{SD})$ & & $35 \pm 13$ & $22.3 \pm 3.0$ & & $16 \pm 9$ & \\
\hline Control group $(n=7 ; \mathrm{m} \pm \mathrm{SD})$ & & $25 \pm 2$ & $22.4 \pm 1.6$ & & & \\
\hline
\end{tabular}

IGT, impaired glucose tolerance; DM, diabetes mellitus.

hypoglycemic agent, while individual N1966 was treated by diet only. Patients received no other medication.

Glucose tolerance status and insulin secretory profile of patients from family F423 were compared with those of six MODY patients carrying a point mutation (PM) in glucokinase gene (Tables I and II). PM patients belong to two kindreds presenting with different mutations (Glu-300-GIn and Gly-175-Arg; reference 9). Seven lean, healthy individuals with no diabetic relatives were also used as a control group (Tables I and II). Patients and individuals in the control group gave fully informed consent before taking part in the study.

Insulin secretion was evaluated by measuring plasma insulin response to an intravenous glucose tolerance test (IVGTT). A bolus of $30 \%$ dextrose $(0.5 \mathrm{~g} / \mathrm{kg}$ body wt $)$ was injected over $3 \mathrm{~min}$. Time 0 was the end of the injection. Blood was sampled for glucose and insulin measurements at $-5,1,3,5,10$, and $15 \mathrm{~min}$. First-phase insulin secretion was expressed as the sum of the values of $1+3 \mathrm{~min}$ as this has become a standard representation of IVGTT results (16).

Plasma insulin was measured by radio immunoassay. Plasma glucose was measured by the glucose-oxidase method (glucose analyzer II; Beckman Instruments, Inc., Fullerton, California). Data are expressed as mean $\pm S D$. Statistics are Mann-Whitney's $U$ test for nonparametric data. IVGTT and hyperglycemic clamp data from PM patients and from individuals N2234 and N2235 were previously reported elsewhere (17).

SSCP (single-strand conformation polymorphism) analysis. Genomic DNA was isolated from peripheral blood leukocytes using stan- dard procedures (18). Molecular scanning for mutations in GCK was done by PCR amplification of each of the 12 exons of the glucokinase gene (7), followed by SSCP analysis as described (19).

Automatic direct sequencing. PCR amplified genomic DNA fragments (the normal and the deleted alleles) were isolated using a kit (Qiagen, Coger, France), before direct double-stranded DNA sequencing. The different cDNA-PCR products (the normal and the aberrant transcripts) were isolated from low-melting agarose by aspirating directly the band visualized by ethidium bromide staining. DNA templates were sequenced directly using a DNA sequencer (373A; Applied Biosystems, Foster City, CA), and a dideoxy-cycle-sequencing protocol in the presence of the specific primers together with fluorescence-labeled dideoxy terminators according to Sanger (20).

cDNA synthesis to detect illegitimate transcription. EBV-transformed lymphocytes from both affected and unaffected individuals were cultured and total RNA was prepared according to the method of Chirgwin et al. (21). cDNA synthesis was carried out as described (22). The yield of PCR product from reverse transcribed GCK CDNA was increased specifically by two rounds of PCR amplification using a pair of external primers, D1 and D2, for the first round and a couple of internal (nested) primers, D3 and D4 to enhance the specificity and the product yield (Fig. 1). The complementary sequences for the PCR primers D2 and D4 were in exon 6 and those for D1 and D3 were in exon 2 (Fig. 1). The PCR amplification is as follows: $10 \mu$ l of the $40-\mu$ ] reaction mix containing the reverse transcribed GCK cDNA strands were added to a $50-\mu$ l volume containing $20 \mathrm{pmol}$ of PCR primers D1

Table II. Metabolic Profile of GCK-defective Patients in Family F423

\begin{tabular}{|c|c|c|c|c|c|}
\hline \multirow[b]{2}{*}{ Patients } & \multirow[b]{2}{*}{$\mathrm{Hb} \mathrm{AlC}$} & \multicolumn{3}{|c|}{ OGTT } & \multirow{2}{*}{ 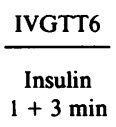 } \\
\hline & & $\begin{array}{c}\text { Glucose } \\
0 \mathrm{~min}\end{array}$ & $\begin{array}{l}\text { Glucose } \\
120 \mathrm{~min}\end{array}$ & $\begin{array}{l}\text { Glucose } \\
\text { surface }\end{array}$ & \\
\hline & $\%$ & mmol/liter & mmol/liter & mmol/liter & mU/liter \\
\hline N1966 & 6.1 & 6.7 & 8.8 & 1212 & 105 \\
\hline $\mathrm{N} 2234$ & 6.1 & 6.3 & 11.2 & 1443 & $21^{*}$ \\
\hline $\mathrm{N} 2235$ & 6.1 & 9.4 & 12.5 & 1361 & $85^{*}$ \\
\hline $\mathrm{N} 2687$ & 6.4 & 8.4 & 11.3 & 1595 & 28 \\
\hline $\mathrm{F} 423(\mathrm{~m} \pm \mathrm{SD})$ & $6.2 \pm 0.2$ & $7.7 \pm 1.5$ & $11.0 \pm 1.6$ & $1403 \pm 160$ & $60 \pm 42$ \\
\hline PM patients $(n=6 ; \mathrm{m} \pm \mathrm{SD})^{*}$ & $6.1 \pm 0.2$ & $6.8 \pm 0.5$ & $8.8 \pm 2.2$ & $1118 \pm 190$ & $92 \pm 35$ \\
\hline Statistics (F423 vs. PM) & $P=0.22$ & $P=0.34$ & $P=0.14$ & $P=0.05$ & $P=0.09$ \\
\hline Control group $(n=7 ; \mathrm{m} \pm \mathrm{SD})$ & & $5.1 \pm 0.6$ & $4.3 \pm 0.8$ & $707 \pm 113$ & $151 \pm 96$ \\
\hline Statistics (F423 vs. control group) & & $P=0.01$ & $P=0.01$ & $P=0.01$ & $P=0.09$ \\
\hline
\end{tabular}

$\mathrm{Hb}$ AlC stands for glycated hemoglobin A1C; standard values in our laboratory for nondiabetic subjects: $4.9 \pm 0.7 \%$. Glucose surface is the area under the glucose curve during the OGTT (0 to $120 \mathrm{~min}$ ). * Data reprinted from reference 17 . Statistics are Mann-Whitney's U test. 


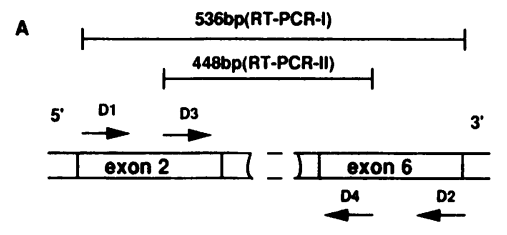

B $\mathbf{N}^{\circ}$ Location

D1 107 GgatgcagaAgGagatgac

D2 642 5' GTAGCAgGagatcatcGtgG 3'

D4 611
D3 164 5' 'TGAagatgctgccCACctaC 3'

Figure 1. PCR amplification of cDNA from the GCK gene. $(A)$ Schematic representation of exons 2-6 and the design of the two RT-PCR-reactions, RTPCR-I and RT-PCR-II, where the arrows represent the primers, pointing to the direction of the extension reaction. The normal size of the RT-PCR products is shown. ( $B)$ Location and sequences of the four primers used for the two RT-PCR reactions. Numbers $\left(\mathrm{N}^{\circ}\right)$ refer to the location of the first 5 ' nucleotide based on the cDNA sequence of pancreatic isoform of the GCK gene.

and D2, $1 \mathrm{U}$ of Taq DNA polymerase (Boehringer-Mannheim, Mannheim, Germany) and furnished buffer. 30 cycles of PCR amplification were performed, with preheating at $95^{\circ} \mathrm{C}$ for $5 \mathrm{~min}$, denaturation at $92^{\circ} \mathrm{C}$ for $30 \mathrm{~s}$, annealing at $42^{\circ} \mathrm{C}$ for $1 \mathrm{~min}$, extension at $72^{\circ} \mathrm{C}$ for 1.5 min, and a final extension at $72^{\circ} \mathrm{C}$ for $7 \mathrm{~min}$. On completion of this round of PCR amplification (RT [ reverse transcription]-PCR-I), $5 \mu$ l of the reaction mix was used for the second round of PCR amplification (RT-PCR II) in which $8 \mathrm{pmol}$ each of the nested primers D3 and D4 were used in a 50- $\mu$ l volume with $160 \mathrm{mM}$ dNTP, $1 \mathrm{U}$ of the same Taq polymerase and a reaction buffer containing $2 \mathrm{mM} \mathrm{MgCl} 2,20$

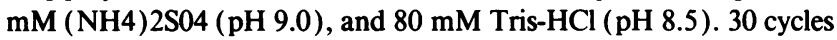
of PCR amplification were performed for the second round PCR, with preheating at $95^{\circ} \mathrm{C}$ for $5 \mathrm{~min}$, denaturation at $92^{\circ} \mathrm{C}$ for $30 \mathrm{~s}$, annealing at $55^{\circ} \mathrm{C}$ for $1 \mathrm{~min}$, extension at $72^{\circ} \mathrm{C}$ for $1.5 \mathrm{~min}$, and a final extension at $72^{\circ} \mathrm{C}$ for $7 \mathrm{~min}$.

Hybridization of product of RT-PCR II with internal oligo-probes. The product of RT-PCR-II was hybridized with internal oligo-probes, D5 (5'-TGACCGGCACTGCTGAGATG-3'), located at the 3' end of exon 3 in the GCK gene, and D6 ( $5^{\prime}$-AGGGAACAATGTCGTGGGGC- $3^{\prime}$ ), located in exon 5. $3 \mu \mathrm{l}$ of the amplified product were electrophoresed on a denaturant (6\% acrylamide, $8 \mathrm{M}$ urea) gel at $75 \mathrm{~W}$, transferred to a N+ nylon membrane (Amersham International, Buckinghamshire, UK), and consequently hybridized with the D5 or D6 oligo-probe, labeled with [ $\alpha-32 \mathrm{P}] \mathrm{dCTP}$ by an amino-terminal transferase kit (Boehringer-Mannheim). The filter was then washed and autoradiographed.

\section{Results}

\section{Molecular scanning of the GCK gene}

The 12 exons of the GCK gene from one affected member of kindred F423 (N2234) were scanned for mutation by SSCPPCR analysis. On exon 4, in addition to a normal migrating band, we found a variant conformer. This conformer cosegregated with diabetes in this family (Fig. 2, $A$ and $C$ ), and was not present in 100 unrelated normoglycemic individuals, nor in 80 unrelated NIDDM patients. Two PCR products of exon 4 were apparent in a $1.5 \%$ agarose gel migration, i.e., a band of normal size ( $273 \mathrm{bp})$ and a shorter one, suggesting the presence of a deletion in the mutant allele (Fig. $2 B$ ).

Identification of an intronic deletion. Direct sequencing of this genomic region in the affected heterozygote $\mathrm{N} 2235$ showed two different sequences: one is the expected normal sequence, the other showed a deletion of $15 \mathrm{bp}$, which removed the $t$ of the gt dinucleotides in the splice donor site of intron 4 , and the following $14 \mathrm{bp}$ (Fig. $3 \mathrm{~B}$ ). The acceptor site and the branch

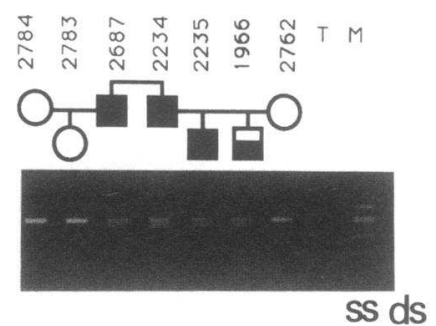

$\mathbf{A}$

Figure 2. Genomic PCR amplification and SSCP analysis of exon 4 of the GCK gene in family F423. $(A)$ Pedigree of kindred F423. Black-

B ened symbols denote diabetic patient, halfblackened symbols designate glucoseintolerant patient. $(B)$

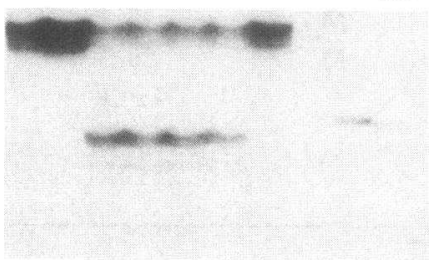

C Agarose gel electrophoresis of genomic PCR amplification of exon 4 region. Lane $T$, control reaction sample in which no DNA was

added. Lane $M$, marker DNA: phiX 174 DNA digested with HaelII. Unaffected individuals showed a single $P C R$ product of the expected size ( $273 \mathrm{bp}$ ). PCR amplification of affected members DNA showed both a normal 273 bp product and an abnormal slightly shorter band. (C) Autoradiography of genomic SSCP analysis by a glycerol-free nondenaturant polyacrylamide gel. SS, denatured single-strand marker DNA (pBR 322 DNA digested with HaelII). DS, double strand marker DNA. The variant conformer segregates without exception with the diabetic phenotype in kindred F423.

site remained unchanged. This heterozygous defect was confirmed after sequencing of the separated alleles (Fig. $3 C$ ). The deletion was present in all affected individuals from family F423 but not in the nonaffected individuals.

\section{Exploration of mRNA in a patient with the intronic deletion}

To investigate the effect of this genomic deletion on the structure and the sequence of the encoding mRNA, lymphoblasts were cultured from one affected individual (N2235) of family F423 and from one unrelated individual. Total RNA was extracted, and cDNA species were synthesized by reverse transcription. The illegitimate specific cDNA region from exon 2 to exon 6 was amplified by PCR, and found to have one band of normal size ( $448 \mathrm{bp}$ ) in the control sample, and four different bands in the patient sample: an upper faint band, a band of 424 bp, a shadow band beneath 424 bp, and a 352-bp band (Fig. 4 $A$ ). The lowest band ( $352 \mathrm{bp}$ ) was likely to be a truncated mRNA lacking the 96 bp exon 5, but the other three bands remained of unknown origin. Southern blot analysis of cDNA products with a labeled internal oligo-probe, D5, located at the $3^{\prime}$ end of exon 3 , confirmed the specificity of the RT-PCR amplification: specific hybridization of both the normal size $448 \mathrm{bp}$ in the control and the two shorter fragments ( 424 and $352 \mathrm{bp}$ ) in the patient, was obtained. Rehybridization of the same blot with an oligo-probe D6 located in exon 5, detected 448 bp band in the control sample; in the patient, the abnormal $424 \mathrm{bp}$ band was seen and the lower aberrant $352 \mathrm{bp}$ transcript was not visualized (data not shown). This favored the hypothesis of the occurrence of an abnormally spliced mRNA in which exon 5 is missing.

The shadow band between 424 bp and 352 bp bands, isolated from agarose gel, and amplified by PCR, gave two separate bands migrating at position $424 \mathrm{bp}$ and $352 \mathrm{bp}$. Direct sequencing of this shadow band confirmed that it was a mixture of two sequences, 424 and $352 \mathrm{bp}$, respectively. This suggested that the shadow band beneath 424 bp was an anomalously migrating heteroduplex molecule, commonly observed 

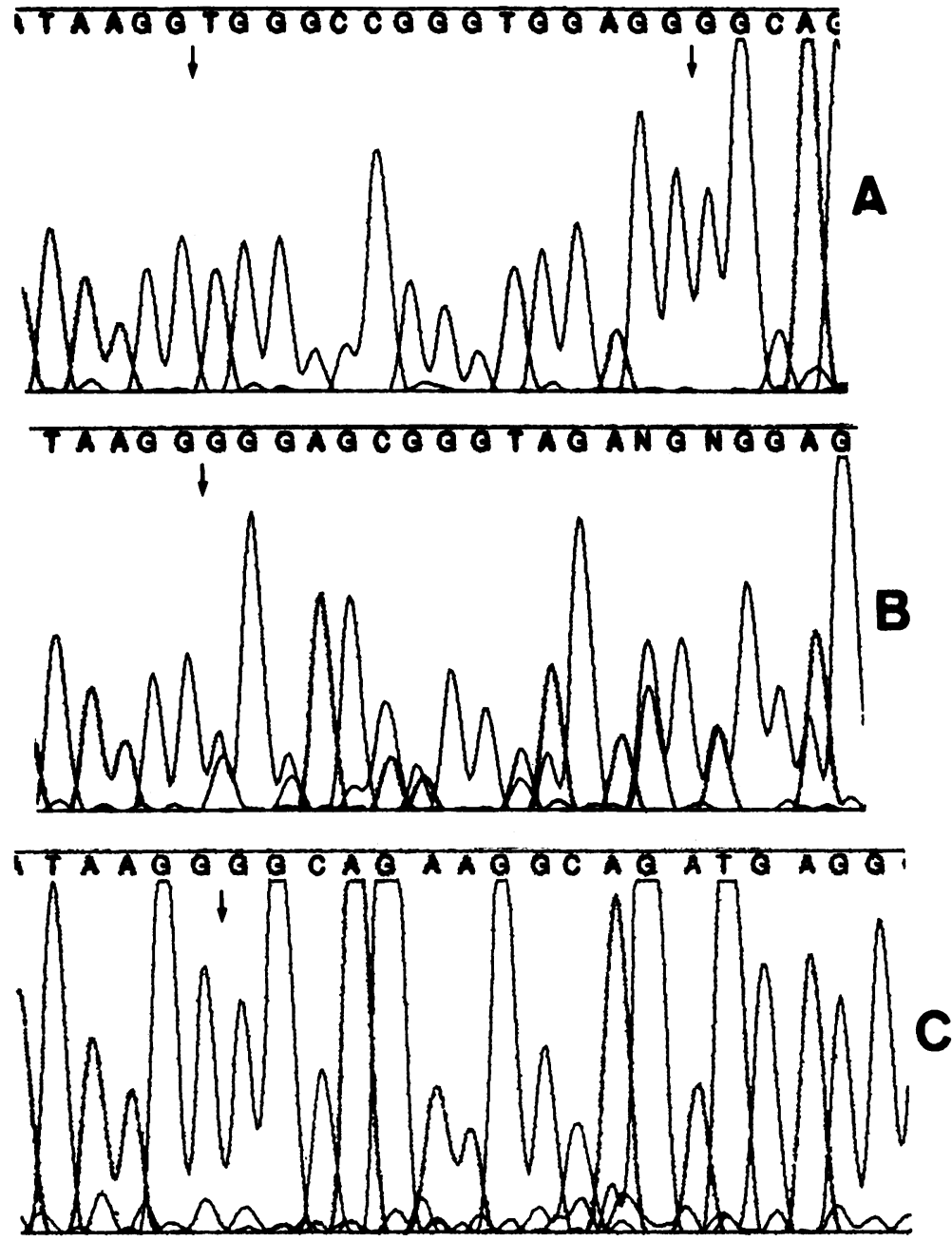

Figure 3. DNA sequence analysis of genomic variants of the GCK gene, in the exon 4-intron 4 boundary region. $(A)$ Normal allele. The two arrows delineate the $15 \mathrm{bp}$ lacking in intron 4 in the affected individuals of the F423 kindred. $(B)$ DNA sequence of an affected patient (N2235) that shows an overlap of two different sequences, the normal allele sequence and the $15 \mathrm{bp}$ deleted allele sequence. The bases assigned by computer after the arrow are a mixture of both sequences. The arrow shows the beginning of the overlap, i.e., the first nucleotide after the 15 bp deletion. $(C)$ DNA sequence of the deleted mutant allele after isolation by Qiagen kit. The arrow indicates the location of the 15 bp deletion in intron 4 . in the presence of mixtures of related products that differ in length (23). The lack of hybridization with probes D5 (Fig. 4 $B$, lane $P$ ) and D6 (data not shown) is best explained by the denaturing condition of gel electrophoresis before blotting. The upper faint band (above $424 \mathrm{bp}$ ) hybridized neither with the
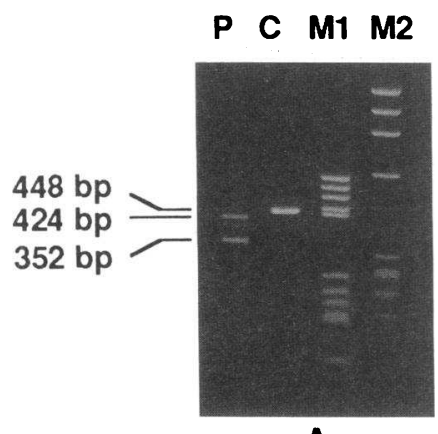

A

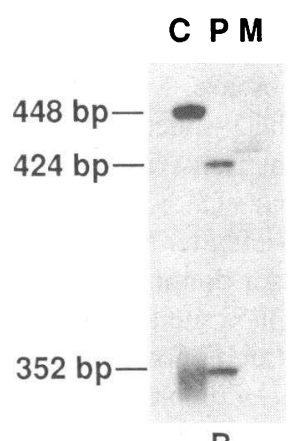

B
Figure 4. Agarose gel electrophoresis of PCR-amplified cDNA and hybridization with an internal oligo-probe. $(A)$ Agarose gel electrophoresis of PCR-amplified cDNA from control and kindred F423 affected individual (N2235). Lane $P$, patient. Lane $C$, control. Lane $M 1$, pBR322 plasmid DNA digested with HaeIII. Lane $M 2$, phiX 174 DNA digested with HaelII. $(B)$ Hybridization of CDNA-PCR products with the inernal oligo-probe, D5, labeled with [ $\alpha-32 \mathrm{P}] \mathrm{dCTP}$. Lane $C$, control. Lane $P$, patient. Lane $M$, pBR322 plasmid DNA digested with HaeIII.
D5 nor with the D6 oligo-probe, suggesting that it could be a nonspecific product of PCR amplifications. Direct sequencing of the 424-bp band and the 352-bp band demonstrated that two different mRNA were transcribed in patient N2235 (Fig. 5): an aberrant mRNA without exon 5 , which resulted in the inframe joining of exon 4 to exon 6 ( $352 \mathrm{bp}$, splice variant I [Fig.

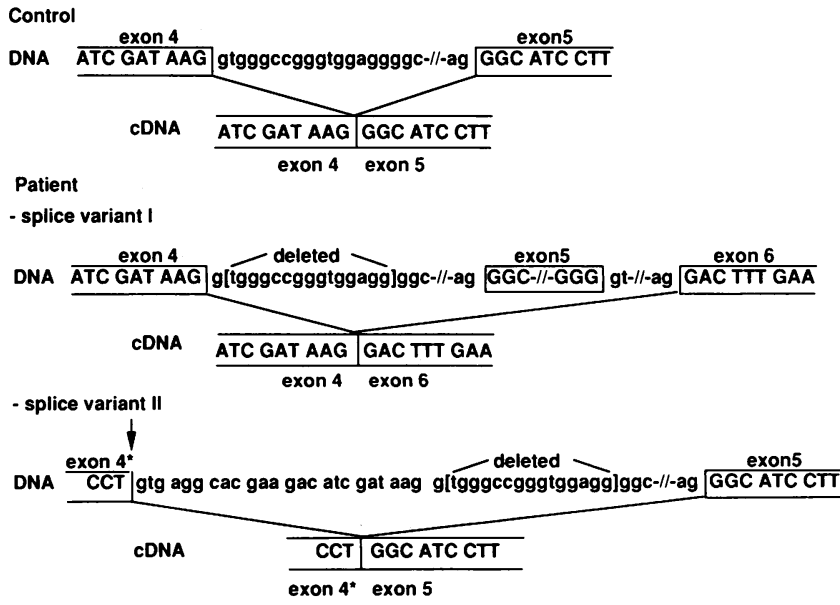

Figure 5. Schema of the alternative splicing resulting in the two aberrant mRNAs observed in the patient N2235. The truncation is indicated by an arrow. Asterisk indicates the truncated exon. 
4, $A$ and $B$; Fig. 5]); and an alternatively spliced mRNA product, resulting from the activation of a cryptic splice site gt, located in exon 4, 24 bp upstream of the consensus site gt ( 424 bp, splice variant II [Fig. 5]). This abnormal mRNA lacks the last eight codons of exon 4 and remains in-frame. To verify whether SSCP has not failed to detect a mutation that alters the splice sites around exon 5, we have sequenced the $3^{\prime}$ end of intron 4 (from 52 bp upstream of exon 5 ) and intron 5 . It was found to be normal in all the diabetic and normoglycemic members of kindred F423 (results not shown).

Five consecutive preparations of products of RT-PCR II were made from the reversed transcribed CDNA, in both patient N2235 and the unrelated control individual. Direct sequencing of the cDNA fragments in the patient showed, in only one experiment out of five, an insertion of the first $10 \mathrm{bp}$ from intron 2 between exon 2 /exon 3 , which was associated with the skipping of exon 5 in the same mRNA molecule (data not shown). This insertion occurred by activation of a gt cryptic splice site $11 \mathrm{bp}$ downstream from the gt consensus donor site. If translated, this aberrant transcript would lead to a frameshift introducing a stop codon (TGA) at the beginning of exon 3 . This insertion was never observed in the control cDNA despite repeated experiments.

\section{Clinical and metabolic profile}

All the individuals in the kindred F423 carrying the deletion described above present with abnormal glucose tolerance ( Table II). Fasting and 2-h plasma glucose were not different in affected individuals from F423 and PM individuals. However, two findings suggest that glucose tolerance was more severely affected in the kindred F423 than in PM patients. First, the area under the glucose curve during the OGTT was significantly larger in F423 individuals than in PM individuals ( Table II). Second, although the glycated hemoglobin was not significantly different in both groups, three out of four patients in F423 against one out of six of the PM patients were treated by hypoglycemic agents. First-phase insulin secretion was not significantly different in the two groups. However, one can note that in the elder individuals of F423 (N2234 and N2687), the first-phase insulin secretion was lower than 1 SD below the mean in PM individuals.

\section{Discussion}

Several nonsense and missense mutations have recently been identified in the GCK gene as a cause of hyperglycemia in MODY $(6,7,9)$ and in a few late-onset NIDDM families (8, $24)$. We here report a deletion in the 5 ' splice site of intron 4 in the GCK gene that is responsible for diabetes in a French MODY family.

Expression studies of mutant alleles of GCK after site-directed mutagenesis would not be possible in the case of an intronic mutation affecting a splice site, until the abnormal mRNAs have been identified. Thus, in individuals of family F423 carrying a deletion in intron 4, it was of interest to analyze the encoded GCK mRNA to understand the molecular basis of the phenotypic effect of this DNA alteration. The glucokinase gene is expressed only in liver and in pancreatic beta cell (12), tissues that are not easily available for investigation in human. Amplification by PCR of illegitimate transcripts has proven to be a sensitive method to scan for mutations in any gene expressed in any cell type (25), even when mutations occurred in highly tissue-specific genes, such as the dystrophin gene (25), the anti-Müllerian hormone gene (26) and the type IV collagen alpha 5 chain gene (22). We have taken advantage of illegitimate transcription to amplify the GCK cDNA from lymphoblastoid cells and to demonstrate that this deletion was seemingly responsible for diabetes in this kindred. Although these abnormalities in GCK mRNA were found in cultured lymphoblastoid cells, it is likely that in pancreas and liver, splicing is similarly impaired. Chelly et al. demonstrated that in regions of the dystrophin gene surrounding different deletions, processing of truncated transcripts were identical in specific (muscle tissue) and in nonspecific cells (lymphoid cells) (27). PCR amplification of lymphoblast mRNA showed two major species of aberrant truncated mRNA: one with the skipping of exon 5 and the other with an activation of a cryptic splice site upstream from the deleted splice site, resulting in the splicing of eight codons at the end of exon 4, but maintaining the reading frame. In patient $\mathrm{N} 2235$, only the aberrant reverse transcripts have been found. We did not succeed in isolating the normal reverse transcript despite repeated efforts. This might be due to limitations of the PCR technique, which, in the case of two differently sized alleles, fail sometimes to amplify the longer allele (B. Knebelmann, unpublished data).

Aberrant splicing, caused by alteration of $5^{\prime}$-splice sites, have been shown previously: Sakuraba et al. reported that of 22 characterized 5'-splice site mutations in various mammalian genes, $77 \%$ resulted in exon skipping, whereas $27 \%$ activated cryptic splice sites ( 28 ). In the MODY family F423, the abnormal 424 bp transcript results from the activation of a cryptic splice site situated in exon 4 , close to and upstream ( $24 \mathrm{bp}$ ) the deleted consensus gt site, as usually reported $(28,29)$. The sequence surrounding this cryptic site (CT gtgagg) is in agreement with the consensus sequence of 5 '-splice site in mammals: AG gta (or g) agt for the positions -2 to +6 based on the beginning of the intron where the splice site is situated. The positions of $-2,-1$, and from +4 to +6 are less important and may have different nucleotides $(28,30)$.

In most cases reported previously $(28,29,31)$, when the 5 '-splice site was altered, the skipped exon was exclusively the exon located on $5^{\prime}$ of the altered donor splice site. The mechanisms involved in family F423, leading to the skipping of the exon situated on $3^{\prime}$ of the affected donor splice site, remain obscure. A possible explanation is that the genomic deletion of the 5'-splice site in intron 4 would affect the normal function of the transcriptional machinery, as it has been described by Leroux et al. (32). The remaining sequence at the 5'-part of intron 4 left after the deletion, gggcag $(+1$ to +6$)$, could be recognized as a donor splice site and used with the intron $53^{\prime}$-acceptor splice site (ag), instead of the intron $43^{\prime}$-acceptor splice site. Rare nonconforming splice sites (i.e., ggaagg $[+1$ to +6$]$ ) have been reported in several genes (30). The third type of aberrant GCK messenger observed (with an insertion of the first $10 \mathrm{bp}$ from intron 2 between exon 2 / exon 3 and the skipping of exon 5) seems to be rare, since we found it in only one RT-PCR experiment out of five. The mechanism that leads to this transcript is unknown.

The genomic deletion in intron 4 of the GCK gene is likely to be responsible for the hyperglycemia in kindred F423 for several reasons: $(a)$ the defect in GCK cosegregated with diabetes in this family, and the likelihood of the odds score (lodscore) for linkage is highly significant $(+4.85$, i.e., odds for 
linkage of almost $10^{5}: 1$, data not shown) using an autosomal dominant model $(6) ;(b)$ this deletion was not present in unrelated normal and late-onset NIDDM individuals; and $(c)$ this deletion resulted in the synthesis of aberrant truncated GCK mRNA species, which probably encode a GCK enzyme with decreased or null activity. A molecular model of the glucokinase protein using the related yeast hexokinase B crystal structure has shown that the region encoded by exon 5 , which is missing in splice variant I (Fig. 5), plays an important role in binding glucose to GCK (10). Indeed, most of the point mutations reported in MODY families are clustered in exons 5, 7, and $8(10)$. The last eight codons of exon 4, which are lacking in splice variant II, encode a beta strand region of the enzyme. Their absence might alter the conformational structure of the enzyme, leading to a decrease of its activity (10). Thus, the putative decrease in GCK activity could account for the hyperglycemic phenotype of affected members of family F423, as GCK is a rate-limiting enzyme for glycolysis in pancreatic beta cell and in liver and is involved in the regulation of insulin secretion and in hepatic glucose uptake $(12,13)$. Since GCK seems to act as a monomer, the insulin secretory defect in heterozygous individuals could be the result of a gene dosage effect. Meglasson and Matschinsky (11) have suggested that a modest decrease in glucokinase activity may shift the threshold for insulin secretion in response to a physiological glucose challenge from 5 to $6 \mathrm{mM}$. In this regard, we have previously demonstrated that mutant GCK in four MODY families (including F423) leads to chronic hyperglycemia by raising the threshold level of circulating glucose, which induces insulin secretion, and by the inability of the pancreatic beta cell to sustain insulin secretion through a prolonged hyperglycemic stimulus (17).

It is difficult to determine the proportion of each transcript of the mutant GCK in patients of family F423, for the method of RT-PCR does not allow quantification of illegitimate transcripts (25). The percentage of splice variants I and II might not be equal from one patient to another in this kindred. It might be speculated that splice variant I (with exon 5 skipped) leads to a more important decrease in the activity of the enzyme than splice variant II (lacking the last eight codons in exon 4). Thus, the proportion of each abnormal transcript might also account for the differences in the severity of the secretory defects observed in different individuals of F423, although other genetic or environmental factors might contribute to this defect.

Different phenotypic expression of mutants of GCK has been reported in MODY families, and it has been suggested that clinical and metabolic characteristics of diabetic patients may reflect the nature and/or the position of the mutation (10). Moreover, expression studies of mutant alleles of GCK have shown that mutations having a mild effect on GCK activity lead to less severe forms of diabetes than mutations resulting in a dramatic decrease of the Vmax of the enzyme (10). The deletion in family F423 probably results in an important decrease of the enzyme activity. This may account for the relatively more severe phenotype of affected members in this family, in comparison with the PM individuals.

We have recently found another intronic deletion in GCK in a 9-yr-old hyperglycemic child, with a strong family history of diabetes. Nucleotide sequencing analysis revealed a deletion of $33 \mathrm{bp}$ in the beginning of intron 5 , which removed the consensus donor splice site gt (with cc instead after the deletion) of intron 5 (data not shown). The association of diabetes with this deletion confirms the deleterious effect on glucose homeostasis of DNA deletions that remove donor splice sites of GCK.

In conclusion, this study demonstrated that a deletion of a donor splice site in intron 4 of the GCK gene causes a form of NIDDM with early age of onset (MODY subtype). Illegitimate transcription of the GCK gene in lymphoblastoid cells can be used to screen for mutation in the GCK gene of diabetic patients and to understand the molecular basis of such mutations, especially in the case of an intronic defect altering normal splicing.

\section{Acknowledgments}

We thank Dr. J. J. Robert for referring family F423 and Dr. P. Czernichow for referring his young diabetic patient, Drs. N. Vionnet and D. Grausz for useful discussions and critical reading of the manuscript, F. Lethrosne and F. Dufour for lymphoblastoid cell cultures, F. Gros and L. Drouot for RNA extraction, and P. Millasseau and L. Baron for technical assistance in sequencing.

This work was supported by the Association Francaise contre les Myopathies through the Genethon program, the Assistance PubliqueHôpitaux de Paris, Boehringer-Mannheim, and the French Ministry for Research and Technology.

\section{References}

1. Rich, S. S. 1990. Mapping genes in diabetes. Genetic epidemiological perspective. Diabetes. 39:1315-1319.

2. Barnett, A. H. 1989. Diabetes, race and genes. Diabetic Medicine. 6:78-83.

3. Fajans, S. S. 1990. Scope and heterogeneous nature of MODY. Diabetes Care. 13:49-64.

4. Froguel, P., M. Vaxillaire, F. Sun, G. Velho, H. Zouali, M. O. Butel, S. Lesage, N. Vionnet, K. Clement, F. Fougerousse et al. 1992. Close linkage of glucokinase locus on chromosome $7 \mathrm{p}$ to early-onset non-insulin-dependent diabetes mellitus. Nature (Lond.). 356:162-164.

5. Hattersley, A. T., R. C. Turner, M. A. Permutt, P. Patel, Y. Tanizawa, K. C. Chiu, S. O'Rahilly, P. J. Watkins, and J. S. Wainscoat. 1992. Linkage of type 2 diabetes to the glucokinase gene. Lancet (N. Am. Ed.). 339:1307-1310.

6. Vionnet, N., M. Stoffel, J. Takeda, K. Yasuda, G. I. Bell, H. Zouali, S. Lesage, G. Velho, F. Iris, P. Passa et al. 1992. Nonsense mutation in the glucokinase gene causes early-onset non-insulin-dependent diabetes mellitus. Nature (Lond.). 356:721-722.

7. Stoffel, M., P. Froguel, J. Takeda, H. Zouali, N. Vionnet, S. Nishi, I. T. Weber, R. W. Harrisson, S. J. Pilkis, S. Lesage et al. 1992. Identification of two missense mutations in glucokinase linked to early-onset non-insulin-dependent diabetes mellitus. Proc. Natl. Acad. Sci. USA. 89:7698-7702.

8. Stoffel, M., P. Patel, Y.-M. D. Lo, A. T. Hattersley, A. M. Lucassen, R. Page, J. I. Bell, G. I. Bell, R. C. Turner, and J. S. Wainscoat. 1992. Missense glucokinase mutation in maturity-onset diabetes of the young and mutation screening in late-onset diabetes. Nature Genetics. 2:153-156.

9. Froguel, P., H. Zouali, N. Vionnet, G. Velho, M. Vaxillaire, F. Sun, S. Lesage, M. Stoffel, J. Takeda, P. Passa et al. 1993. Familial hyperglycemia due to mutations in glucokinase: definition of a subtype of diabetes mellitus. N. Engl. J. Med. 328:697-702.

10. Gidh-Jain, M., J. Takeda, L. Z. Xu, A. J. Lange, N. Vionnet, M. Stoffel, P. Froguel, G. Velho, F. Sun, D. Cohen et al. 1993. Glucokinase mutations associated with non-insulin-dependent ( type 2 ) diabetes mellitus have decreased enzymatic activity: implications for structure/function relationships. Proc. Natl. Acad. Sci. USA. 90:1932-1936.

11. Meglasson, M. D., and F. M. Matschinsky. 1984. New perspectives on pancreatic islet glucokinase. Am. J. Physiol. 256:E1-E13.

12. Matschinsky, F. M. 1990. Glucokinase as glucose sensor and metabolic signal generator in pancreatic beta-cells and hepatocytes. Diabetes. 39:647-652.

13. Magnuson, M. A. 1990. Glucokinase gene structure: functional implications of molecular genetic studies. Diabetes. 39:523-527.

14. Froguel, P., G. Velho, D. Cohen, and P. Passa. 1991. Strategies for the collection of sibling-pair data for genetic studies in type 2 (non insulin-dependent) diabetes mellitus. Diabetologia. 34:685.

15. WHO Expert Committee on Diabetes Mellitus. 1980. Second Report. Technical Report Series 646. World Health Organization, Geneva.

16. Robert, J. J., I. Deschamps, D. Chevenne, M. Roger, A. Mogenel, and C. Boitard. 1991. Relationship between first-phase insulin secretion and age, HLA, 
islet cell antibody status, and development of type 1 diabetes in 220 juvenile first-degree relatives of diabetic patients. Diabetes Care. 14:718-723.

17. Velho, G., P. Froguel, K. Clement, M. E. Pueyo, B. Rakotoambinina, H. Zouali, P. Passa, D. Cohen, and J. J. Robert. 1992. Primary pancreatic beta-cell secretory defect caused by mutations in glucokinase gene in kindreds of maturity onset diabetes of the young. Lancet (N. Am. Ed.). 340:444-448.

18. Blin, N., and D. W. Stafford. 1976. A general method for isolation of high molecular weight DNA from eukaryotes. Nucleic Acids Res. 3:2303.

19. Orita, M., Y. Suzuki, T. Sekiya, and K. Hayashi. 1989. Rapid and sensitive detection of point mutations and DNA polymorphisms using the polymerase chain reaction. Genomics. 5:874-879.

20. Sanger, F., S. Nicklen, and A. R. Coulson. 1977. DNA sequencing with chain-terminating inhibitors. Proc. Natl. Acad. Sci. USA. 74:5463-5467.

21. Chirgwin, J. M., A. E. Przybyla, R. J. MacDonald, and W. J. Rulter. 1979. Isolation of biologically active ribonucleic acids from sources enriched in ribonuclease. Biochemistry. 18:5294-5299.

22. Knebelmann, B., G. Deschenes, F. Gros, M. C. Hors, J. P. Grünfeld, K. Tryggvason, M. C. Gubler, and C. Antignac. 1992. Substitution of arginine for glycine 325 in the collagen $\alpha 5$ (IV) chain associated with x-linked Alport syndrome: characterization of the mutation by direct sequencing of PCR-amplified lymphoblast cDNA fragments. Am. J. Hum. Genet. 51:135-142.

23. Roberts, R. G., M. Bobrow, and D. Bently. 1992. Point mutations in the dystrophin gene. Proc. Natl. Acad. Sci. USA. 89:2331-2335.

24. Katagiri, H., T. Asano, H. Ishihara, K. Inukai, M. Anai, J. I. Miyazaki, K Tsukuda, M. Kikuchi, Y. Yazaki, and Y. Oka. 1992. Nonsense mutation of glucokinase gene in late-onset non insulin dependent diabetes mellitus. Lancet (N. Am. Ed.). 340:1316-1317.
25. Chelly, J., J. P. Concordet, J. C. Kaplan, and A. Kahn. 1989. Illegitimate transcription: transcription of any gene in any cell type. Proc. Natl. Acad. Sci. USA. 86:2617-2621.

26. Knebelmann, B., L. Boussin, D. Guerrier, L. Legeai, A. Kahn, N. Josso, and J. Y. Picard. 1991. Anti-Müllerian hormone Bruxelles: a nonsense mutation associated with the persistent Müllerian duct syndrome. Proc. Natl. Acad. Sci. USA. 88:3767-3771.

27. Chelly, J., H. Gilgenkrantz, J. P. Hugnot, G. Hamard, M. Lambert, D. Récan, S. Akli, M. Cometto, A. Kahn, and J. C. Kaplan. 1991. Illegitimate transcription. Application to the analysis of truncated transcripts of the dystrophin gene in nonmuscle cultured cells from Duchenne and Becker patients. J. Clin. Invest. 88:1161-1166.

28. Sakuraba, H., C. M. Eng, R. J. Desnick, and F. Bishop. 1992. Invariant exon skipping in the human $\alpha$-galactosidase A pre-mRNA: a $g+1$ to $t$ substitution in a 5'-splice site causing Fabry disease. Genomics. 12:643-650.

29. Robberson, B. L., G. L. Cote, and S. M. Berget. 1990. Exon definition may facilitate splice site selection in RNAs with multiple exons. Mol. Cell Biol. 10:8494.

30. Shapiro, M. B., and P. Senapathy. 1987. RNA splice junctions of different classes of eukaryotes: sequence statistics and functional implications in gene expression. Nucleic Acids Res. 15:7155-7174.

31. Talerico, M., and S. M. Berget. 1990. Effects of 5' splice site mutations on splicing of the preceding intron. Mol. Cell. Biol. 10:6299-6305.

32. Leroux, C., N. Mazure, and P. Martin. 1992. Mutations away from splice site recognitions sequences might cis-modulate alternative splicing of goat $\alpha_{\mathbf{s} 1}$-casein transcripts. J. Biol. Chem. 267:6147-6157. 